\title{
Sustainability and Resilience Assessment in the Pandemic Emergency
}

\author{
Gabriella Arcese*, Marzia Traverso **
}

\begin{abstract}
The coronavirus pandemic has affected all production and service sectors. The crisis has led to the increased awareness of the fragility and vulnerability of our societies and our lifestyles.

The speed at which it spreads has led first to a change of our behavior and our way oflife but at the same time, it has also changed the way we consider our buildings and how we live in them. Considering the new visions aimed at sharing spaces, such as those of work with the coworking spaces or frontal lessons in the classroom, they must now be rethought. In tourism and catering, relations with customers are reviewed and public transport is radically rethought. In this context, the concept of resilience plays a key role.

How resistant are we and our environment to crises like COVID-19? What is the significance of resilience in sustainability? Is there a link between the assessment of resilience and life cycle assessment?

In this paper is represented a general framework to connect resilience and sustainability assessments.
\end{abstract}

Keywords: Sustainability; Resilience, Crisis; Life Cycle Sustainability Assessment; Covid-19; Global Markets

\section{Sustainability and Assessment: the Starting Point}

In the last decade, the interest in sustainability impact assessment of products and companies has significantly increased as well as the identification of social risks and potentials to improve (Lucchetti, Arcese, Traverso, \& Montauti, 2018). This is a significant methodology towards a more sustainable development.

The most well-known definition of sustainable development is given by the Brundtland Commission: "A development that meets the needs of the present without compromising the ability of future generations to meet their own needs" (WCED 1987, Chapter 2, from A742/427).

\footnotetext{
* Gabriella Arcese, Associate Professor of Business Management, Niccolò Cusano University (gabriella.arcese@unicusano.it)

** Marzia Traverso, Full Professor of Sustainability in Civil Engineering, RWTH Aachen University, Germany (marzia.traverso@inab.rwth-aachen.de)
}

Edited by: Niccolò Cusano University

ISSN: $1593-0319$

Arcese, G., \& Traverso, M. (2021). Sustainability and Resilience Assessment in the Pandemic Emergency. Symphonya. Emerging Issues in Management (symphonya.unicusano.it), (2), 99-117.

https://dx.doi.org/10.4468/2021.2.09arcese.traverso 
In general, business, and economic ecosystem are characterized by a certain degree of vulnerability. This vulnerability is usually due to shocks, such as an economic crisis, natural disasters, wars and, more recently, biological risks such as COVID-19 (G. Arcese, Valeri, Poponi, \& Elmo, 2020).

Small and Medium Sized business activities (SME) are present in different commercial sectors and can be generally found in small cities, small towns, and municipalities. In this period, in Italy but also in the rest of Europe, they are characterized by negative economic cycles, strongly affected by the pandemic condition (Bellandi, 2020).

The upward trend of urbanisation characterised by a rapidly growing number of city dwellers (Goddard,2021) and an increasing population density is exacerbating sustainability issues such as air and water pollution, insufficient public waste management and dependence on non-renewable energy sources, but also issues affecting the quality of citizens' life such as congestion, inadequate development of public transport systems and the lack of digitalisation of public services (Gabriella Arcese, Schabel, Elmo, \& Risso, 2019). The current model of city development is in contrast with what today are the main forms of fighting the pandemic, such as social distancing, isolation, and individual forms of work such as smart working at home.

One method to assess the sustainability performance of products and/or services is life cycle sustainability assessment (LCSA), which assesses product performance considering the environmental, economic, and social dimensions over the life cycle (Finkbeiner et al., 2010; Traverso et al., 2012). Even if the LCSA methodology was defined about 10 years ago, it has not been standardized yet. Moreover, this methodology and its indicators do not assess resilience the importance of which has increased when considering climate change and pandemic phenomena such as COVID-19.

Considering this, the authors wonder:

RQ1: How resistant are (we and) our environment to crises like COVID-19?

RQ2: What is the significance of resilience in sustainability?

RQ3: Is there a link between the quantification of resilience and the life cycle assessment?

Resilience in sustainability assessments and in the Life Cycle Sustainability Assessment context will be proposed.

Aim of this research work is to identify if there is a link between the resilience concept and sustainability evaluation and, in particular, if there is evidence of a relationship between resilience and sustainability assessment through Life Cycle Sustainability Assessment (hereafter LCSA).

The paper is organized as follows. paragraph 2 shows the materials and the methods, it examines the characteristics and sources of the data used for the analysis. Paragraph 3 illustrates the theoretical background, and paragraph 4 describes the results obtained from the literature review. In paragraph 5, results are discussed and in paragraph 6 some conclusions are drawn. 


\section{Materials and Methods}

To develop the topic and understand if there is a link between Resilience and Sustainability, the authors conducted an extensive literature review considering the scientific papers published in international journals and contained mainly in scientific database in the last years. At the same time, bibliometric analysis, and content scenario was design based also on the new crisis due to the SARS-CoV-2.

The authors extract content and structural analysis on the collected sources by main scientific databases (EBSCO, Scopus, Thomson Reuter, etc.). The integration between quantitative and qualitative approach was used. Based on a systematic literature review, the analysis was conducted using statistical criteria and bibliometric indicators.

This is a quantitative approach, in fact indicators are used: basic or normalized such as Hirsh index (h-index) is the most known indicator and, similarly to the Science Citation Index, measures the impact of the authors through its impact factor (IF) and advanced or network indicators. The screening of the sources was done using specific criteria and keywords (Sidiropoulos, Katsaros, \& Manolopoulos, 2007).

In detail, authors integrate several tools: systematic literature review, bibliometric analysis, and automatic text analysis (ATA) tools.

The use of ATA tools and the analysis of the lexicon for the identification of the key words was useful. It allowed us to draw out the major topics discussed and articles published in various periods in order to select those areas of interest, i.e. those that contain innovation issues. We conducted a principal component analysis (PCA) to classify the different approaches and to outline their guidelines in the research (Arcese et al., 2018)

Finally, from this analysis, the correlation between Resilience, Sustainability and Life cycle sustainability assessment is discussed.

After a comprehensive analysis of the main scientific sources, the authors concentrated the analysis of a sample of papers extracts from the Scopus database.

The final query is the following:

TITLE-ABS-EY (resilience AND sustainability AND crisis) AND RECENT (14) including the words in Article title, Abstract, Keywords Add additional search terms with and not limited to articles or reviews (last access on November 2020).

The final sample contains 47 scientific contributions. No time limit was assigned to this research. The publications were subdivided by year as follows: 45 papers were published in 2020 and 2 paper schedules in publishing for 2021. In detail, 34 of these papers are scientific papers, 6 are reviews and the rest are classified as follows: 1 conference paper, 1 editorial and 1 letter. Final and published paper are 36, the other 9 are in press.

The articles contained in the sample were collected and analysed and the results were summarised in the follow section. The bibliometric and content analysis will be discussed. 


\section{Theoretical Analysis}

The search for a link between the concept of resilience and that of sustainability turns out to be an extremely attractive research topic and not a new exploration. At the bases of these research there is the Ecology and the Industrial Ecology (as consequence) because the Sustainability and the Resilience concepts historically are based on a quantitative and engineering approach ("Resilience and sustainability," 2019). Walker et al., (2004) introduced the change in the paradigm and redefine the concept with the research paper "Resilience, Adaptability and Transformability in Social-Ecological Systems" based on Holling's seminal paper (1973) (Walker, Holling, Carpenter, \& Kinzig, 2004).

From the point of view extrapolated from the Holling theories, the system is based in conditions of equilibrium, and we analyse how quickly the system, after a disturbance, returns to equilibrium. Conversely, many ecological and socioecological systems may spend more time out of equilibrium and in several possible states ("stable alternative"). The flexibility of the concept manifests a complexity of analysis and the often-changing nature of their context. Indeed, keeping context in mind is of prime importance in analysing how close resilience and sustainability are (Walker et al., 2004).

This is done mainly because the systems (industrial, social and environmental) are considered to be connected to each other. Talking today, therefore, of a resilience model with a single technical approach would be reductive.

In fact, if we consider all the actions implemented in recent years to reduce environmental impacts and the consumption of resources, we realize that efforts are often in vain and global unsustainability does not stop. The ecosystem is a complexity of variables that include political choices, business strategies and the introduction of new technologies.

Considering the upcoming pandemic crisis, it is fair to consider resilience from new points of view. An interesting approach come from (Fiksel, 2006), where the systemic and global approach to sustainability. The assumption at the base of Fiksel model is the concept of resilience has emerged as a critical characteristic of complex, dynamic systems in a range of disciplines including economics (Fiksel, 2006). Integrated approach in this case means including in the same communication system biocomplexity, environmental engineering, life cycle analysis and protection ecosystem service. These variables are combined with the economic and social variables such as stocks and flows, and include production, consumption, infrastructure and population behaviours.

Holling (1973, p.14) defined resilience as "a measure of the persistence of systems and of their ability to absorb change and disturbance and still maintain the same relationships between populations or state variables". This approach is perceived as a system that withstands, reacts and adapts to changing conditions (Schoon, 2005).

Resilience is a property of systems essential for sustainability (Darestani et al., 2021; Pizzol, 2015). Indeed, according to several authors (D'adamo and Rosa, 2020; Sarkis, 2020) resilience and sustainability are related concepts.

Several researches identified cases where resilience plays a key role for sustainability as well as in climate change adaptation in cities (Hunt and Watkiss 2011), water management (Pizzol et al., 2013), urban management (Zhang et al., 
2012), resource management (EEA 2012), energy security of gas supply (Scotti and Vedres 2012), distributed economies (Johansson et al., 2005; Mirata et al., 2005).

Figure 1: System Dynamic Model Fiksel (2006)

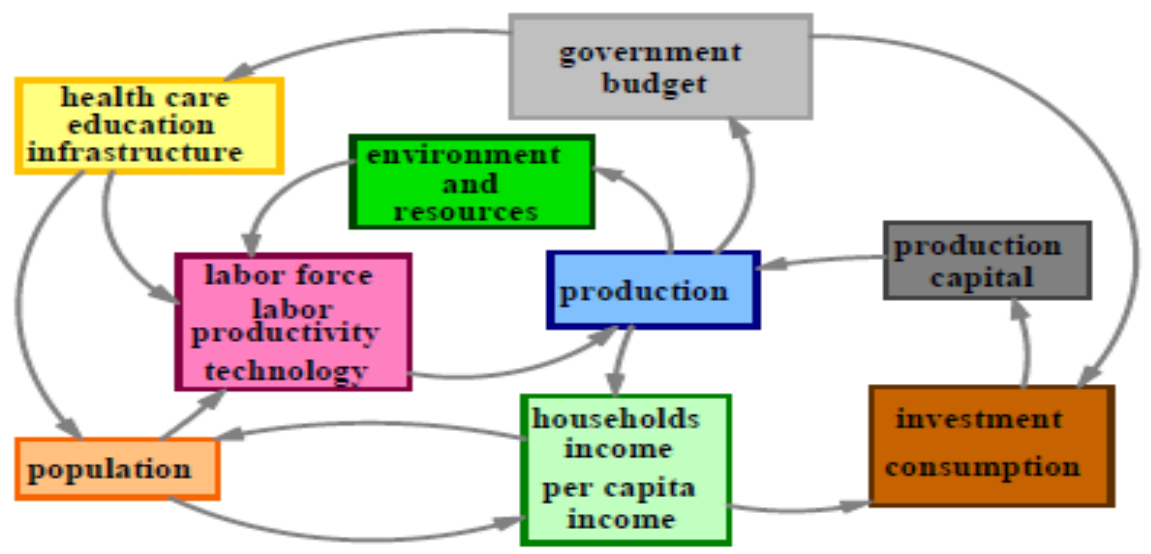

Source: Fiksel, 2006.

Due to Covid-19 and to pursue the path to sustainability, the industrial sector must assess the risks in product development and production processes by implementing a resilient system (Diaz-Elsayed et al., 2020). Barbosa (2021) has identified the resilience as a new research opportunity given the need to create a resilient ecosystem in order to re-establish a link with consumers. It's essential to build resilience through risk-informed sustainable development to recovery from Covid-19, which aims to generate sustainable and resilient communities.

The Covid-19 outbreak represents an opportunity to implement sustainable practices reducing and managing several risks. In addition, Pizzol et al. (2015) show that increasing product systems' resilience does not necessarily lead to a decrease in their ecoefficiency.

However, the issue of resilience is not explored in Life Cycle Assessment (LCA) studies. Few researchers have mentioned LCA in connection with design for resilience (Fiksel 2003; Korhonen and Seager 2008; Mu et al., 2011; Seager 2008; Kou and Zhao 2011).

Companies to pursue the trend of sustainability should design solutions that take into account the impacts of climate change and have the ability to adapt to changing conditions after Covid-19 (O'Connell and Hou, 2015). For instance, the existing literature highlighted that enhancing resilience to global environmental change (Song et al., 2019) is an emerging research trend as it is a theme that remains unexplored (Al-Tabbaa et al., 2007; Simon, 2015; Worthy et al., 2013).

Since 2000, LCM considers only the environmental impacts, and it is linked at Life Cycle Assessment applications. In 2002, Heiskanen considers LCA as an accounting model and a "social planner's view on environmental issues, rather than the minimization of a company's direct environmental liabilities".

The LCM framework represents the triple bottom line (3BL), that is a model that integrates the "three dimensions of sustainability: economic, environmental and social" and cover the three Ps: people, planet and profit (Remmen et al., 2007) (Figure 2). 
Figure 2: The Triple Bottom Line

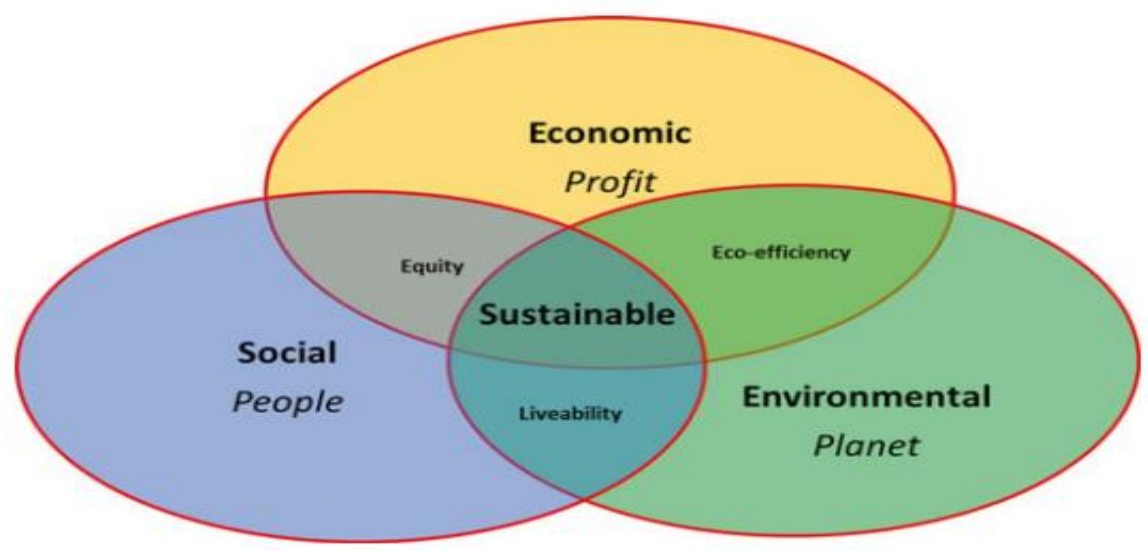

Source: Our elaboration based on Agenda 21'2 Sustainable Development.

LCSA is an evaluation procedure that measures product performance with regard to environment, economy, and society. The accepted model for applying LCSA is defined by equation (1) (Traverso et al., 2012) (Finkbeiner et al., 2010; Kloepffer 2003, 2008):

$$
\mathrm{LCSA}=\mathrm{LCA}+\mathrm{LCC}+\mathrm{S}-\mathrm{LCA}
$$

The formal equation indicates that to assess the sustainability performance of products over the whole life cycle, a complementary approach of environmental life cycle assessment (LCA), life cycle costing (LCC), and social life cycle assessment (S-LCA) should be implemented with a consistent system boundary and by reporting all results in the same functional unit. Whereas LCC assesses economic impacts (Swarr et al., 2011, Rebitzer \& Hunkeler 2003), S-LCA (Jørgensen et al., 2010) is the assessment of positive and negative social impacts of products.

The term resilience has been used freely across a wide range of academic disciplines and in many different contexts. There is little consensus regarding what resilience is, what it means for organisations and, more importantly, how organisations might achieve greater resilience in the face of increasing threats (Resilient Organisations, 2007).

The Covid-19 pandemic has inevitably led us to reconsider these concepts and to look for a useful integration that can be used in times of crisis like this we are experiencing.

\section{Results from Bibliometric Analysis}

Starting from the bibliometric analysis results, the model proposed by Madani \& Weber, (2016) was used. In this model the authors, the most publications and mentions for the topic were analysed. Unfortunately, the bibliometric analysis used as starting point, it doesn't help to find the specific research's lines at this stage. It is probably because there is not a large number of contributions on the topic and few 
authors (maximum two search by authors), or affiliate (maximum two studies). Among the universities that are dealing with these related issues we can find:

- University of Nottingham;

- Aristotle University of Thessaloniki;

- The University of Tennessee, Knoxville

- Rikkyo University;

- Keio University;

- Center For Research and Technology - Hellas;

- Hochschule für Wirtschaft und Recht Berlin.

The main authors are the following.

Andrew DeWit (with Shaw, R., Djalante, R.) with two works that talk about resilience at the time of Covid-19. The first, "An integrated approach to sustainable development, National Resilience, and COVID-19 responses: The case of Japan" by DeWit, A., Shaw , R., Djalante, R. is published in the International Journal of Disaster Risk Reduction. The research is a rapid analysis of emerging information provided by the government of Japan and other international organizations. Using the case of Japan, this paper suggests that it is possible both to protect public health and essential services, while also promoting resilience and sustainability. Japan's integrated solutions show that pandemic response can include accelerated decarbonization and resilient, sustainable development.

The second study, "Building resilience against biological hazards and pandemics: COVID-19 and its implications for the Sendai Framework" by the same research group as the previous one, examines the relationship between pandemic and sustainable development goals and uses the health-emergency disaster risk management (HealthEDRM) framework as a risk management model.

Donald Housing, former editor in chief of Journal of cleaner production, appears in the literature review with the study: "From multidisciplinarity to transdisciplinarity and from local to global foci: Integrative approaches to systemic resilience based upon the value of life in the context of environmental and gender vulnerabilities with a special focus upon the brazilian amazon biome" co-authored by Zabaniotou, A., Syrgiannis, C., Gasperin, D., de Hoyos Guevera, A. J., Fazenda, I. The paper shows the benefits of a workshop-based methodology for developing a vision and an approach to the inner processes of creation that can be used to increase resilience, to cope with societal vulnerabilities and to develop the tools for future planning at local, regional and global scales.

The second paper "Now is the time to press the reset button: Helping India's companies to become more resilient and effective in overcoming the impacts of COVID-19, climate changes and other crises" with Khurana, S., Haleem, A., Luthra, $\mathrm{S}$, and Mannan, B., talk about and used of essential factors which can help companies to overcome this crisis and other types of crises, by learning from the approaches taken in India, which has a unique and diverse economic system. The Analytical Hierarchy Process (AHP) technique was used to identify the essential factors which can help companies to improve their resilience so they can recover during and after the COVID19 pandemic era and potentially in other similar complex crises. The "Role of governance" was found to be the most important factor that can be used to help in rebuilding businesses and societies and in helping them to become more resilient to future serious shocks. 
Finally, Dmitry Aleksandrovich Ivanov from Hochschule für Wirtschaft und Recht Berlin has published in Annal of Operation Research, papers on the incidence of pandemic crisis on the supply chain. First research titled Viable supply chain model: integrating agility, resilience and sustainability perspectives-lessons from and thinking beyond the COVID-19 pandemic theorizes a new notion-the viable supply chain (VSC) and demonstrates how the VSC components can be categorized across organizational, informational, process-functional, technological, and financial structures. And in the second study "Impacts of epidemic outbreaks on supply chains: mapping a research agenda amid the COVID-19 pandemic through a structured literature review" co-authored by Queiroz, M.M, Dolgui, A., Fosso Wamba, S., conducting a literature review on humanitarian logistics, that is, on the movement of people, has thoroughly investigated the impacts of the epidemic and points out the gaps in the solution and suggestions for managing this type of crisis.

A large number of these research come from United States (n.15 documents), other relevant countries are United Kingdom, Germany and Japan. Only 3 documents come from Italy so far.

Interesting considerations concern the subject areas of the research in the sample. The economic-managerial perspective appears as evident in the research and the results show that this problem is mainly related to these disciplines. It should be noted that some searches may have multiple subject area labels, but thirty papers are labelled as social science and are joined with another 11 belonging to the category "Business, Management and Accounting", 4 in "Economics, Econometrics and Finance" to highlight how the conception of resilience is becoming broader and less of engineering.

The sample made up of 47 articles were analysed also with VosViewer (van Eck and Waltman, 2010). The software allowed the authors to create a visual representation, on the other hands, maps based of the most recurring terms in the title and abstracts, in bibliographic sources, and in co-occurrences. This form of analysis, known as science mapping, is used to visually characterize the structure of a research section and create a possible future scenario (Cobo et al., 2011; Richard Klavans and Kevin W. Boyack, 2006). The results of the analysis show 10 items, grouped in 3 clusters and 43 links.

Figure 3 shows a term co-occurrence map based on text data, which was obtained by using binary counting with 8 times as the minimum number of occurrences. We were able to extract 10 terms with a relevance score (presented below).

The map shows the grouping and links between the 3-cluster pattern obtained. Cluster 1 (red) comprises 4 words that can be connected to the word "resilience". In particular, the cluster includes the main topic of the research and connect "covid-19", and the words "epidemic" and "sustainability". The cluster analysis underlines the research contained terms used by researchers to define a reference "framework" and the actual review and state of arts.

Cluster 2 (blue) refers to words associated with the macro theme "Sustainable development". This theme includes aspects related to "viral disease" and "climate change".

Cluster 3 (green) comprised terms related to the "corona virus disease" concept. The cluster includes human and pandemic research linked to the environment and biological aspects. 
Figure 3: Text Analysis Binary on Title and Abstract

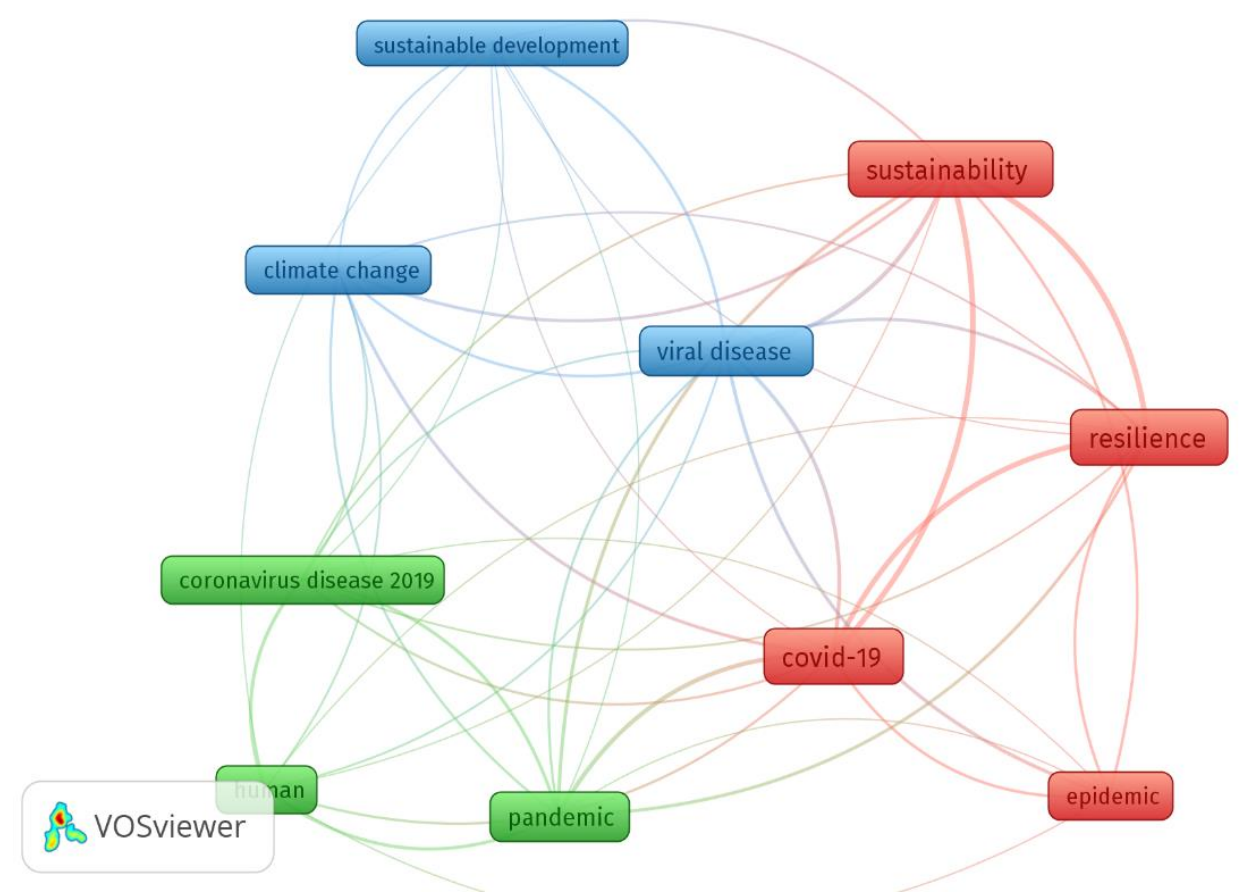

Source: Authors' elaboration with sw VosViewer.

\subsection{Results From Textual Analysis}

The textual analysis (ATA) uses qualitative approaches for identified items and key terms or topics in which there is no need for representative samples for analysis (Notarnicola, Tassielli, Renzulli, Arcese, \& Di Capua, 2016). ATA is a tool for understanding social phenomena. Today, it is used in a multidisciplinary way and considering many trends. Often it is used for supporting literature review. Among the various approaches that can be used to conduct the textual analysis, the most common is based on the so-called grounded theory Poponi, Arcese, Mosconi, \& Di Trifiletti, 2020).

In this specific case, the sample created for bibliometric analysis is used as empirical basis., where ground stands for basic research. The data are coded and analysed through the allocation of labels that represent the concepts identified as a function of specific characteristics and through a process in which the affinity between data generates categories, i.e., groups of abstract concepts (Baxter, 2014).

The result of this type of analysis is a representation in node. This method of textual analysis follows the steps of automatic text analysis based following past literature review conducted with this tool, as in the paper (Arcese et al., 2018). The extraction of information is automated by the lexical analysis instruments that allow the operation of the query for classes of text (in this case scientific articles) by using homogeneous criteria and nodes of information. Before performing the ATA, the texts are selected and collected through the construction of nodes or categories and collected in a database (Arcese et al., 2020).

In the node results words correspondent to the item of the cluster findings throughout the bibliometric analysis. For this reason, these words were analysed. 
For the cluster red the four keywords have a node but there is not particular evidence of concept because are the keywork at the bases of the sample creation. For the word "epidemic" there is no specific node, but the word occurs 152 times in the sample the incidence.

For the green cluster, the interesting results contribution come from the node "human". Most of the papers analysed compared under the node having correction withe words "human" can be traced back to 3 topics: link between pandemic and population, link between behaviour of economic agents and pandemic, human behaviour in the social context of cities in relation to the environmental impact during lockdowns.

For the cluster blue, the node "Sustainable" and "Development", "Viral Disease" and "Climate Change". Ten papers in the sample are identified in correlation with sustainability and the Covid-19. Specific results are obtained for the paper "The COVID-19 pandemic: Impacts on cities and major lessons for urban planning, design, and management" (Sharifi, A., \& Khavarian-Garmsir, A. R.,2020). The concentration of numerous studies on populations and economic activities shows how these are hotspots for cities. The results of this study demonstrate how the impacts of COVID19 on cities are related to some main themes: environmental quality, socio-economic impacts, public management and governance, transport, and urban design. In relation to socioeconomic factors, post-COVID urban planning and design can be used. Resilience is represented in this case by the vision of COVID-19 as an opportunity to undertake transformational actions towards the creation of sustainable cities. The aforementioned study and others show that air quality is directly related to the incidence of the pandemic, particularly the air quality.

Other interesting concepts are deduced from the paper "Reconstructing tourism in the Caribbean: connecting pandemic recovery, climate resilience and sustainable tourism through mobility justice" by Sheller (2020); in this research the concept of sustainability is linked to the problem of climate change and the Covid-19 pandemic. Rebuilding tourism infrastructure has often been a major focus of international development aid and regional government responses to natural disasters.

The ecologies and economies of tourist territories will be more sustainable when we emerge from the pandemic. Through an analysis of the "climate coloniality" it focuses on a critique of disaster tourism during these "unnatural disasters" and allows to redefine the ethical and political implications of the resumption of tourism when other mobility such as immigration are severely reduced. Through the concept of "mobility justice" to address the problem of sustainability transitions in relation to tourism mobility, climate change and disaster recovery and considers post-disaster reconstruction as an opportunity to improve sustainability.

Lastly, another scientific work that links sustainability and resilience through the climate change is entitled "Resilience and sustainability: a complementary relationship? Towards a practical conceptual model for the sustainability - resilience nexus in tourism" by Espiner et al. (2017) also focused on the sector tourist.

It states how the concept of "resilience" is in some way comparable to the concept of sustainability in the tourism sector. It has generated fascination in the academic tourism literature as a term that could capture key aspects of sustainability, while acknowledging the considerable influences that multiple contexts have on the capacity of communities of people and ultimately support their tourism businesses. The concept 
of resilience includes an inclusive and integrative approach of "social ecological systems" which gives a solid interdisciplinary foundation in its application in tourism.

The last aspect considered in the ATA is the evaluation of the impacts within our sample. There is no evidence in studies of the consideration of assessment or the use of sustainability assessments. Furthermore, there is no evaluation model, based or not on life cycle analysis, which assesses resilience.

\section{Discussion}

The aim of this paper is to propose a general framework to connect Resilience and sustainability assessments. The following section provide answers to the initial research questions.

\section{RQ1: How resistant are (we and) our environment to crises like COVID-19?}

The incidence of the pandemic on the environment produced and is producing contrasting impacts. In response to the pandemic, partial and total lockdowns were enforced in many parts of the world. Most of the papers reviewed focus on impacts related to the environment and onair pollution and climate change (Ciciotti, 2020).

These lockdowns provided an unprecedented opportunity to test how major transportation policy (Tuffs, 2020) interventions and reforms in production patterns may contribute to enhance urban air quality (Kerimray et al., 2020). In the end, it should be reiterated that this crisis highlights the need for critical reflections on the importance of cities, business and people.

RQ2: What is the significance of resilience in sustainability?

As Fiksel says (2006):

$\square$ "Sustainable development in a changing global environment will require resilience at many levels, including human communities and economic enterprises. In the face of everincreasing global complexity and volatility, it is essential to move beyond a simplistic "steady state" model of sustainability".

There is a direct correlation between Resilience and Sustainability, also because major studies focus their attention on the ecosystem condition and on the resilience as a quantitative approach for the equilibrium of it.

The bibliometric study of Barbosa (2021) shown how risk and sustainable supply chain management is explored in the literature and identifies resilience as a new research topic. In supply chain management, it is crucial to develop and implement a resilient approach to manage the different risks of disruption. For instance, in the agri-food supply chain, risks are related to meteorological, environmental, logistic/infrastructure, market, regulatory, financial and operational/managerial factors (Zhao et al., 2020). Implementing resilience could generate competitive advantage (Bottani et al., 2019).

Sustainable production represents a strategy that holistically considers economic, environmental and social impacts (Folke et al., 2010). Indeed, a company with sustainable production is resilient by respecting the environment and promoting 
global management. Through international standards, it is possible to implement more environmentally friendly production within companies (Brundage et al., 2018).

\section{RQ3: Is there a link between the quantification of resilience and Life Cycle} Assessment?

No, there is no evidence of Life Cycle Assessment approach in the quantification of resilience.

The evolution of the studies conducted at this time reflects different aspects of the pandemic crisis but there is research with an overview of the different aspects or that include a global perspective and analysis of the matter.

The bibliometric analysis underscores this consideration, and the ATA also confirmed the bibliometrics analysis results included. Now, relevant themes, such as the direct relationship between resilience and sustainability are not considering the Covid-19.

Sustainable production can generate greater resilience favorable to both workers and the environment (e.g., by reducing the impact of outsourcing) (Diaz-Elsayed et al., 2020).

To be resilient, a company introduces ideological and operational changes focusing on sustainability and favoring the continuity of operations. Diaz-Elsayed et al. (2020) proposed the formalization of continuity of operations programs (COOP) such as those promoted within the Department of Defense and the Federal Emergency Management Agency (FEMA, 2020). Like the ISO 9001 certification, these certificates could encourage manufacturers to adopt sustainable, resilient practices. The COOP certificates identify companies with skills and equipment within their supply chains capable of managing and reducing risks (Diaz-Elsayed et al., 2020).

Furthermore, the increase in waste emerges among the consequences generated by the health crisis. In light of this, implementing materials and components' recovery, recycling, and reuse processes support long-term resilience and sustainability (DiazElsayed et al., 2020).

In addition, collaborative technologies such as blockchain technology support building resilience through sharing information (Saberi et al., 2019; van Hoek, 2019).

\section{Conclusions and Future Outlook}

Since the early days of the COVID-19 crisis, the scientific community has constantly been striving to shed light on various issues such as the mechanisms driving the spread of the virus, its environmental and socio-economic impacts, and necessary recovery and adaptation plans and policies ((Sharifi, A., \& Khavarian-Garmsir, A. R.,2020).

Sustainable development cannot be achieved without the involvement of industries and consumers for more sustainable production and consumption. A life cycle thinking is the best approach to assess products and encourage this involvement. With life cycle thinking, potential impacts of a product life cycle are assessed and evaluated.

Dynamic modelling, including biocomplexity, systems dynamics and thermodynamic analyses to investigate the impacts on ecological systems and humans of major changes such as climate change and the associated political and technological responses, should be included in global sustainability assessments that take into 
account economic mutations and the link between the economic and environmentalnatural ecosystems (Fiksel, 2006).

Furthermore, the issue of resilience is addressed in several contexts.

The studies on airport infrastructure focus on analysing greenhouse gas emissions from airport sidewalks and energy management strategies for airport buildings. However, in this field few studies emerge on climate change resilience and waste management. Greer et al. (2020) highlighted how low-emission electricity supply and electrification of ground transportation and access equipment could help airports pursue sustainability goals in the short term. Future studies need to analyze stakeholder engagement, life cycle assessment, linking environmental impacts with operational results and global challenges such as implementing a resilient approach (Greer et al., 2020).

The resilience of airports to the impacts of climate change is a very little studied topic. Relevant risks that airports in coastal locations will face include the impacts of sea-level rise and the increased frequency of flood events (Burbidge, 2016, Poo et al., 2018). Furthermore, Greer et al. (2020) review highlighted the lack of explicit and quantifiable sustainability indicators that investigate building resilience infrastructure's energy and environmental implications (such as marine dams).

In the food field, it requires reducing producer-consumer distances to increase resilience to exogenous shocks, stimulating urban land-use food innovations, exploring new crop options for a changing climate, and creating policies and standards that ensure local production is not more emission-intensive than imports (Newell and Dale 2020). For instance, diversifying operations increase resilience in the agriculture context by harvesting multiple products, even when a particular crop is impacted by the market or environmental changes (Rotz and Fraser 2015).

El Chami et al. (2020) study deepen how sustainable agriculture increase resilience to climate change. However, climate change impacts and resilience of agro-systems are influenced by local conditions (environmental, socio-economic, and management), affecting sustainable agriculture (Scialabba et al., 2010). To enhance resilience and promote sustainable practices, it's pivotal to use an ecosystem-based approach on a life-cycle basis using the LCA method. In light of this, the literature has highlighted the need to enrich research on the connection between LCA and resilience (El Chami et al., 2020; Sumane et al., 2018).

Focusing the global sustainability assessment on life cycle approach helps to provide more complete information useful for the continuous search of new balances to achieve progress in the sustainable management of complex systems.

The economic-managerial cutting appears as evident in the research and the results shows as this is problem is mainly related to these disciplines.

The gap highlighted in the literature shows that there is a need to create a resilience assessment tool based on the global sustainability variable. Life cycle sustainability assessment and its tools (Life cycle assessment, life cycle costing and social life cycle assessment) could provide indicators to create a framework for the crisis management and resilience evaluation. Figure 4 shows the general framework that needs to be developed.

To ensure operational continuity, always but particularly in times of crisis, the will to pursue strategies in the name of environmental sustainability are now essential values for a successful business. Life Cycle Sustainability Assessment is the most 
comprehensive tool for sustainability assessments currently available (Neugebauer et al., 2014).

Figure 4: General Framework: LCSA Integration in Resilience Evaluation

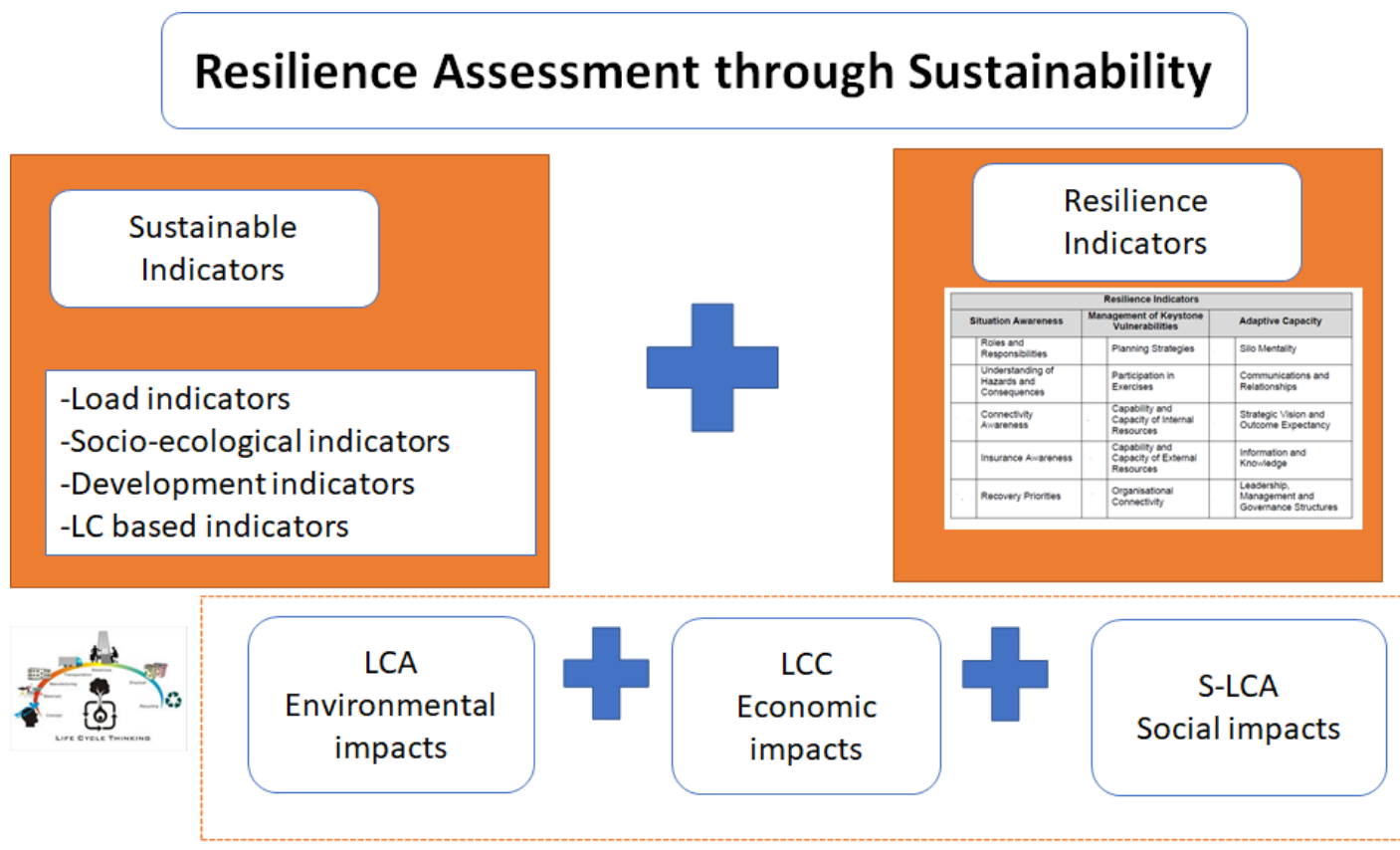

\section{Crisis Management}

\section{Bibliography}

Al-Tabbaa, A., De Munck, C. S., Dixon, T., Doak, J., Garvin, S. L., \& Raco, M. (2007). Climate Change, Pollutant Linkage and Brownfield Regeneration, in Dixon, T., Raco, M., Catney, P., \& Lerner, D. (eds.), Sustainable Brownfield Regeneration: Liveable Places from Problem Spaces (pp. 265-314). Blackwell Publishing.

Arcese, G., Lucchetti, M. C., Massa, I., \& Valente, C. (2018). State of the art in S-LCA: Integrating Literature Review and Automatic Text Analysis. International Journal of Life Cycle Assessment, 23(3).

http://dx.doi.org/10.1007/s11367-016-1082-0

Arcese, G., Valeri, M., Poponi, S., \& Elmo, G. C. (2020). Innovative Drivers for Family Business Models in Tourism. Journal of Family Business Management.

http://dx.doi.org/10.1108/JFBM-05-2020-0043

Arcese, Gabriella, Schabel, L., Elmo, G. C., \& Risso, M. (2019). Smart City in Europe: Comparative Analysis Between Italy and Germany Development. International Journal of Environmental Policy and Decision Making, 2(4), 330.

http://dx.doi.org/10.1504/ijepdm.2019.110329

Barbosa, M. W. (2021). Uncovering Research Streams on Agri-Food Supply Chain Management: A Bibliometric Study. Global Food Security, 28, 100517.

http://dx.doi.org/10.1016/j.gfs.2021.100517

Baxter, J. A. (2010). Discourse-analytic approaches to text and talk, in Litosseliti, L. (ed.), Research Methods in Linguistics (pp. 117-137). Continuum. 
http://www.continuumbooks.com/books/detail.aspx?BookId=124940\&SearchType=Basic

Bellandi, M. (2020). Some Notes on the Impacts of Covid-19 on Italian SME Productive Systems. Symphonya. Emerging Issues in Management (symphonya.unicusano.it), (2), 63-72.

http://dx.doi.org/10.4468/2020.2.07bellandi

Bottani, E., Murino, T., Schiavo, M., \& Akkerman, R. (2019). Resilient Food Supply Chain Design: Modelling Framework and Metaheuristic Solution Approach. Computers \& Industrial Engineering, 135, 177-198.

http://dx.doi.org/10.1016/j.cie.2019.05.011

Brundage, M., Avin, S., Clark, J., Toner, H., Eckersley, P., Garfinkel, B., Dafoe, A., Scharre, P., Zeithoff, T., Filar, B., Anderson, H. Roff, H., Allen, G. C., Steinhardt, J., Flynn, C., Heigeartaigh, S., Beard, S., Belfield, H. Farquhar, S., Lyle, C., Crootof, R., Evans, O., Page, M., Bryson, J., Yampolskiy, R., \& Amodei, D. (2018). The Malicious Use of Artificial Intelligence: Forecasting, Prevention, and Mitigation. arXiv preprint arXiv: 1802.07228

Burbidge, R. (2016). Aviation Climate Resilience: Clarifying the Impacts and Identifying the Barriers. International Journal of Aviation Management, 3(2-3), 88-104.

Ciciotti, E. (2020). A New Territorial-Industrial Policy After the Covid 19 Crisis. Symphonya. Emerging Issues in Management (symphonya.unicusano.it), (2), 25-32.

Cobo, M. J., López-Herrera, A. G., Herrera-Viedma, E., \& Herrera, F. (2011). Science Mapping Software Tools: Review, Analysis, and Cooperative Study AmongTools. Journal of the American Society for Information Science and Technology, 49(July), 327-355.

http://dx.doi.org/10.1002/asi.21525

Cobo, M. J., López-Herrera, A. G., Herrera-Viedma, E., \& Herrera, F. (2011). Science Mapping Software Tools: Review, Analysis, and Cooperative Study Among Tools. Journal of the American Society for Information Science and Technology, 62(7), 1382-1402.

Coffel, E. D., Thompson, T. R., \& Horton, R. M. (2017). The Impacts of Rising Temperatures on Aircraft Takeoff Performance. Climatic Change, 144(2), 381-388.

http://dx.doi.org/10.1007/s10584-017-2018-9

D’Adamo, I., \& Rosa, P. (2020). How do you see Infrastructure? Green Energy to Provide Economic Growth after COVID-19, Sustainability, 12(11), 4738.

http://dx.doi.org/10.3390/su12114738

Darestani, Y. M., Sanny, K., Shafieezadeh, A., \& Fereshtehnejad, E. (2021). Life Cycle Resilience Quantification and Enhancement of Power Distribution Systems: A Risk-based Approach. Structural Safety, 90, 102075. http://dx.doi.org/10.1016/j.strusafe.2021.102075

DeWit, A., Shaw, R., \& Djalante, R. (2020). An Integrated Approach to Sustainable Development, National Resilience, and COVID-19 Responses: The Case of Japan. International Journal of Disaster Risk Reduction. 51, December.

http://dx.doi.org/10.1016\%2Fj.ijdrr.2020.101808

Diaz-Elsayed, N., Rezaei, N., Ndiaye, A., \& Zhang, Q. (2020). Trends in the Environmental and Economic Sustainability of Wastewater-Based Resource Recovery: A Review. Journal of Cleaner Production, (7), 265.

http://dx.doi.org/10.1016/j.jclepro.2020.121598

Djalante, R., Shaw, R., \& DeWit, A. (2020). Building Resilience Against Biological Hazards and Pandemics: COVID-19 and its Implications for the Sendai Framework. Progress in Disaster Science, 100080.

EEA (European Environment Agency) (2012). Environmental Indicator Report 2012-Ecosystem Resilience and Resource Efficiency in a Green Economy in Europe. Copenhagen: European Environment Agency

El Chami, D., Daccache, A., \& El Moujabber, M. (2020). How can Sustainable Agriculture Increase Climate Resilience? A Systematic Review. Sustainability, 12(8), 3119.

http://dx.doi.org/10.3390/su12083119 
Espiner, S., Orchiston, C., \& Higham, J. (2017). Resilience and Sustainability: A Complementary Relationship? Towards a Practical Conceptual Model for the Sustainability-Resilience Nexus in Tourism. Journal of Sustainable Tourism, 25(10), 1385-1400.

FEMA, “Continuity Guidance Circular - February 2018," (2018). FEMA National Continuit Programs, available at:

https://www.fema.gov/sites/default/files/2020-07/Continuity-Guidance-Circular_031218.pdf.

Fiksel, J. (2003). Designing Resilient, Sustainable Systems. Environmental Science \& Technology, 37(23), 5330-5339.

http://dx.doi.org/10.1021/es0344819

Fiksel, J. (2006). Sustainability and Resilience: Toward a Systems Approach. Sustainability: Science, Practice and Policy, 2(2), 14-21.

http://dx.doi.org/10.1080/15487733.2006.11907980

Finkbeiner, M.; Schau, E.M.; Lehmann, A.; Traverso, M. (2010). Towards Life Cycle Sustainability Assessment. Sustainability 2010, 2, 3309-3322.

Folke, C., Carpenter, S. R., Walker, B., Scheffer, M., Chapin, T., \& Rockström, J. (2010). Resilience Thinking: Integrating Resilience, Adaptability and Transformability. Ecology and Society, 15(4).

Greer, F., Rakas, J., \& Horvath, A. (2020). Airports and Environmental Sustainability: A Comprehensive Review. Environmental Research Letters, 15(10), 103007.

Goddard, J. (2021). Covid-19. Civic Universities, Societal Innovation and the Recovery of Local Communities. Symphonya. Emerging Issues in Management (symphonya.unicusano.it), (1), 56-63.

Holling, C. S. (1973). Resilience and Stability of Ecological Systems. Annual Review of Ecology and Systematics, 4(1), 1-23.

Holling, C. S. 1973. Resilience and Stability of Ecological Systems. Annual Review of Ecological Systems, 4, 1-23.

Hunt, A., \& Watkiss, P. (2011). Climate Change Impacts and Adaptation in Cities: A Review of the Literature. Climatic Change, 104(1), 13-49.

http://dx.doi.org/10.1007/s10584-010-9975-6

Ivanov, D. (2020). Viable Supply Chain Model: Integrating Agility, Resilience and Sustainability Perspectives-Lessons From and Thinking Beyond the COVID-19 Pandemic. Annals of Operations Research, 1.

Johansson, A., P. Kisch, and M. Mirata (2005). Distributed Economies-A New Engine for Innovation. Journal of Cleaner Production, 13(10-11), 971-979.

http://dx.doi.org/10.1016/j.jclepro.2004.12.015

Kerimray, A., Baimatova, N., Ibragimova, O. P., Bukenov, B., Kenessov, B., Plotitsyn, P., \& Karaca, F. (2020). Assessing air Quality Changes in Large Cities During COVID-19 Lockdowns: The Impacts of Traffic-Free Urban Conditions in Almaty, Kazakhstan. Science of the Total Environment, 139179.

Khurana, S., Haleem, A., Luthra, S., Huisingh, D., \& Mannan, B. (2021). Now is the Time to Press the Reset Button: Helping India's Companies to Become More Resilient and Effective in Overcoming the Impacts of COVID-19, Climate Changes and Other Crises. Journal of Cleaner Production, 280, 124466.

Klavans, R., \& Boyack, K. W. (2006). Identifying a Better Measure of Relatedness for Mapping Science. Journal of the American Society for Information Science and Technology, 57(2), 251-263.

Korhonen, J., \& Seager, T. P. (2008). Beyond Eco-Efficiency: A Resilience Perspective. Strategic Sustainability Management, 17(7), 411-419.

http://dx.doi.org/10.1002/bse.635

Kou, N. and F. Zhao. (2011). Effect of Multiple-Feedstock Strategy on the Economic and Environmental Performance of Thermochemical Ethanol Production under Extreme Weather Conditions. Biomass and Bioenergy, 35(1), 608-616.

http://dx.doi.org/10.1016/j.biombioe.2010.10.023 
Lucchetti, M. C., Arcese, G., Traverso, M., \& Montauti, C. (2018). S-LCA Applications: A Case Studies Analysis. E3S Web of Conferences. (74).

http://dx.doi.org/10.1051/e3sconf/20187410009

Madani, F., \& Weber, C. (2016). The Evolution of Patent Mining: Applying Bibliometrics Analysis and Keyword Network Analysis. World Patent Information, 46, 32-48.

http://dx.doi.org/10.1016/j.wpi.2016.05.008

Mirata, M., H. Nilsson, and J. Kuisma. (2005). Production Systems Aligned with Distributed Economies: Examples from Energy and Biomass Sectors. Journal of Cleaner Production, 13(1011), 981-991.

http://dx.doi.org/10.1016/j.jclepro.2004.12.018

Mu, D., T. P. Seager, P. S. Rao, J. Park, and F. Zhao. (2011). A Resilience Perspective on Biofuel Production. Integrated Environmental Assessment and Management, 7(3), 348-359.

http://dx.doi.org/10.1002/ieam.165

Newell, R., \& Dale, A. (2020). COVID-19 and Climate Change: An Integrated Perspective. Cities \& Health, 1-5.

http://dx.doi.org/10.1080/23748834.2020.1778844

O'Connell, S., \& Hou, D. (2015). Resilience: a New Consideration for Environmental Remediation in an Era of Climate Change. Remediation Journal, 26(1), 57-67.

http://dx.doi.org/10.1002/rem.21449

Pizzol, M. (2015). Life Cycle Assessment and the Resilience of Product Systems. Journal of Industrial Ecology, 19(2), 296-306.

http://dx.doi.org/10.1111/jiec.12254

Pizzol, M., Scotti, M., \& Thomsen, M. (2013). Network Analysis as a Tool for Assessing Environmental Sustainability: Applying the Ecosystem Perspective to a Danish Water Management System. Journal of Environmental Management, 118, 21-31.

http://dx.doi.org/10.1016/j.jenvman.2012.12.042

Poo M C-P, Yang Z, Dimitriu D and Qu Z. (2018). Review on Seaport and Airport Adaptation to Climate Change: A Case On Sea Level Rise And Flooding. Marine Technology Society Journal, 52(2), 23-33.

http://dx.doi.org/10.4031/MTSJ.52.2.4

Poponi, S., Arcese, G., Mosconi, E. M., \& Di Trifiletti, M. A. (2020). Entrepreneurial Drivers for the Development of the Circular Business Model: The Role of Academic Spin-Off. Sustainability (Switzerland), 12(1).

http://dx.doi.org/10.3390/su12010423

Queiroz, M. M., Ivanov, D., Dolgui, A., \& Wamba, S. F. (2020). Impacts of Epidemic Outbreaks on Supply Chains: Mapping a Research Agenda Amid the COVID-19 Pandemic Through a Structured Literature Review. Annals of Operations Research, 1-38.

Resilience and Sustainability (2019). Nature Sustainability, 2(4), 249.

http://dx.doi.org/10.1038/s41893-019-0284-4

Richard Klavans, \& Kevin W. Boyack. (2006). Identifying a Better Measure of Relatedness for Mapping Science. Journal of the American Society for Information Science and Technology, 57(July), 261-263.

http://dx.doi.org/10.1002/asi

Saberi, S., Kouhizadeh, M., Sarkis, J., \& Shen, L. (2019). Blockchain Technology and its Relationships to Sustainable Supply Chain Management. International Journal of Production Research, 57(7), 2117-2135.

http://dx.doi.org/10.1080/00207543.2018.1533261

Sarkis, J. (2020). Supply Chain Sustainability: Learning from the COVID-19 Pandemic. International Journal of Operations \& Production Management, 1(1), 63-73.

http://dx.doi.org/10.1108/IJOPM-08-2020-0568 
Schoon M. (2005). A Short Historical Overview of the Concepts of Resilience, Vulnerability and Adaptation. Working Paper W05-4, Workshop in Political theory and Policy Analysis, Indiana University. Available from URL:

https://michaelschoon.files.wordpress.com/2011/05/historical_critique-of-resilience-workingpaper.pdf

Scialabba, N.E.H., Müller-Lindenlauf, M. (2010). Organic Agriculture and Climate Change. Renewable Agriculture and Food Systems, 25, 158-169.

http://dx.doi.org/10.1017/S1742170510000116

Scotti, M. and B. Vedres. (2012). Supply Security in the European Natural Gas Pipeline Network. In Networks in Social Policy Problems, edited by B. Vedres and M. Scotti. Cambridge, UK: Cambridge University Press

Seager, T. P. (2008). The Sustainability Spectrum and the Sciences of Sustainability. Business Strategy and the Environment, 17(7), 444-453.

http://dx.doi.org/10.1002/bse.632

Sharifi, A., \& Khavarian-Garmsir, A. R. (2020). The COVID-19 Pandemic: Impacts on Cities and Major Lessons for Urban Planning, Design, and Management. Science of The Total Environment, 142391.

Sheller, M. (2020). Reconstructing Tourism in the Caribbean: Connecting Pandemic Recovery, Climate Resilience and Sustainable Tourism Through Mobility Justice. Journal of Sustainable Tourism, (29), 9, 1436-1449.

http://dx.doi.org/10.1080/09669582.2020.1791141

Sidiropoulos, A., Katsaros, D., \& Manolopoulos, Y. (2007). Generalized Hirsch H-Index for Disclosing Latent Facts in Citation Networks. Scientometrics, 72(2), 253-280.

http://dx.doi.org/10.1007/s11192-007-1722-z

Swarr, T. E., Hunkeler, D., Klöpffer, W., Pesonen, H. L., Ciroth, A., Brent, A. C., \& Pagan, R. (2011). Environmental Life-Cycle Costing: a Code of Practice.

Simon, J. A. (2015). Editor's Perspective - The Effects of Climate Change Adaptation Planning on Remediation Programs. Remediation, 25(3), 1-7.

http://dx.doi.org/10.1002/rem.21429

Song, J., Chang, Z., Li, W., Feng, Z., Wu, J., Cao, Q., \& Liu, J. (2019). Resilience-Vulnerability balance to Urban Flooding: A Case Study in a Densely Populated Coastal City in China. Cities, 95, 102381.

http://dx.doi.org/10.1016/j.cities.2019.06.012

Šumane S., Kunda I., Knickel K., Strauss A., Tisenkopts T., des los Rios I., Rivera M., Chebach T., Ashkenazy A. (2018). Local and Farmers Knowledge Matters! How Integrating Informal and Formal Knowledge Enhances Sustainable and Resilient Agriculture. Journal of Rural Studies, 59, 232-241.

http://dx.doi.org/10.1016/j.jrurstud.2017.01.020

Traverso, M., Finkbeiner, M., Jørgensen, A., \& Schneider, L. (2012). Life Cycle Sustainability Dashboard. Journal of Industrial Ecology, 16(5), 680-688.

http://dx.doi.org/10.1111/j.1530-9290.2012.00497.x

Tuffs, R., Larosse, J., \& Corpakis, D. (2020). Post-Covid-19 Recovery Policies: Place-Based and Sustainable Strategies. Symphonya. Emerging Issues in Management (symphonya.unicusano.it), (2), 55-62.

http://dx.doi.org/10.4468/2020.2.06tuffs.larosse.corpakis

Van Eck, N. J., \& Waltman, L. (2010). Software Survey: VOSviewer, a Computer Program for Bibliometric Mapping. Scientometrics, 84(2), 523-538.

Van Hoek, R., Fugate, B., Davletshin, M. and Waller, M.A. (2019), Integrating Blockchain into Supply Chain Management, Kogan Page, London. 
Worthy, R., Abkowitz, M. D., \& Clarke, J. H. (2015). A Systematic Approach to the Evaluation of RCRA Disposal Facilities under Future Climate-Induced Events. Remediation, 25(2), 71-81.

http://dx.doi.org/10.1002/rem.21425

Walker, B., Holling, C. S., Carpenter, S. R., \& Kinzig, A. (2004). Resilience, Adaptability and Transformability in Social-Ecological Systems. Ecology and Society, 9(2).

http://dx.doi.org/10.5751/ES-00650-09020

Zabaniotou, A., Syrgiannis, C., Gasperin, D., de Hoyos Guevera, A. J., Fazenda, I., \& Huisingh, D. (2020). From Multidisciplinarity to Transdisciplinarity and From Local to Global Foci: Integrative Approaches to Systemic Resilience Based Upon the Value of Life in the Context of Environmental and Gender Vulnerabilities with a Special Focus Upon the Brazilian Amazon Biome. Sustainability, 12(20), 8407.

http://dx.doi.org/10.3390/su12208407

Zhang, Y., H. Liu, Y. Li, Z. Yang, S. Li, and N. Yang. (2012). Ecological Network Analysis of China's Societal Metabolism. Journal of Environmental Management, 93(1), 254-263.

http://dx.doi.org/10.1016/j.jenvman.2011.09.013

Zhao, G., Liu, S., Lopez, C., Chen, H., Lu, H., Mangla, S. K., \& Elgueta, S. (2020). Risk Analysis of the Agri-Food Supply Chain: A Multi-Method Approach. International Journal of Production Research, 58(16), 4851-4876.

http://dx.doi.org/10.1080/00207543.2020.1725684 